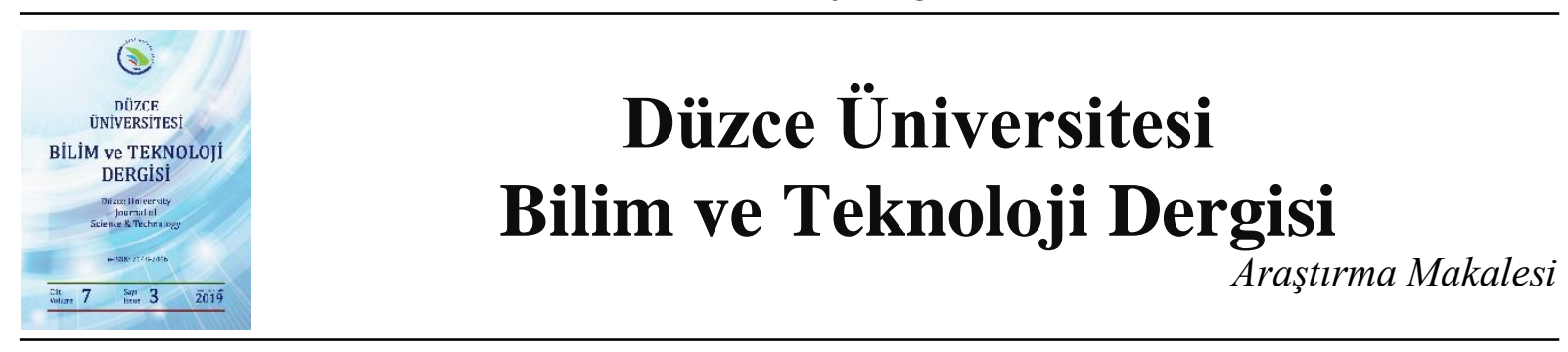

\title{
PMDI İlaveli Melamin Üre Formaldehit (MÜF) Tutkalının Yongalevha Endüstrisinde Değerlendirilmesi
}

\author{
(iD) Halil İbrahim ŞAHİN ${ }^{\mathrm{a}, *}$, (iD) Volkan ÇAVDAR ${ }^{\mathrm{b}}$ \\ ${ }^{a}$ Orman Endüstri Mühendisliği Bölümü, Orman Fakültesi, Düzce Üniversitesi, Düzce, TÜRKIYE \\ ${ }^{b}$ Orman Endüstri Mühendisi, Kastamonu Entegre Ăgaç Sanayi Tic. A.Ş., Kocaeli, TÜRKIYE \\ * Sorumlu yazarın e-posta adresi: halilibrahimsahin@duzce.edu.tr
}

DOI : $10.29130 /$ dubited.577372

\begin{abstract}
$\underline{\text { ÖZET }}$
$\mathrm{Bu}$ çalışmada, nemli şartlarda kullanılan ve yük taşıyıcı olmayan yongalevhalarda PMDI tutkalının kullanılabilirliği araştıılmıştır. Bu amaçla PMDI tutkalı, farklı katılım oranlarında (\%0-Kontrol, 0.5, 0.75, 1, 1.5 ve 2) yongalevhaların orta tabakalarına ilave edilmiştir. Levha üretiminde kullanılan endüstriyel yongalar; $\% 15$ ladin, \%50 çam, \%20 meşe, \%10 kapak tahtası, \%5'i atık talaştan oluşmaktadır. Yoğunluk değeri $630 \mathrm{~kg} / \mathrm{m}^{3}$ olan, \%65'lik melamin üre formaldehit (MÜF) tutkalı kullanılarak yongalevhalar üretilmiştir. Levhaların bazı fiziksel (yoğunluk, rutubet, 2-24 saat kalınlık artımı ve su alma oranı) ve mekanik özellikleri (eğilme direnci, eğilmede elastikiyeti modülü, yapışma direnci, yüzey sağlamlığ 1 ve vida tutma direnci) TS EN standartlarına göre test edilmiştir. Deney sonuçlarına göre test levhalarının 24 saatlik kalınlık artış değerleri, \%14'ün altında tespit edilmiştir. Vida tutma direnci dışındaki tüm mekanik özellikler bakımından test ve kontrol levhaları arasında istatistiksel olarak anlamlı bir farkın olmadığı anlaşılmıştır. Levhaların tüm fiziksel ve mekanik özelliklerine ait değerleri, TS EN 312 (2012) standardında belirtilen P3 tipi (nemli şartlarda kullanılan yük taşıyıcı olmayan levhalar) kullanım alanlarında aranan minimum gereksinimleri karşıladığını göstermiştir.
\end{abstract}

Anahtar Kelimeler: Yongalevha, PMDI tutkall, Melamin üre formaldehit tutkall.

\section{The Evaluation of PMDI Added Melamine Urea Formaldehyde (MUF) Resin in Particleboard Industry}

\begin{abstract}
$\underline{\text { ABSTRACT }}$
In this study, the availability of PMDI resin for non-load bearing particleboard for use in humid conditions was investigated. For this purpose, PMDI resin was added to the middle layers of the boards at different participation rates ( $0 \%$ Control, $0.5,0.75,1,1.5$ and 2). Industrial chips used in particleboard production that it consists of $15 \%$ spruce, $50 \%$ pine, $20 \%$ oak, $10 \%$ slab, $5 \%$ sawdust. Particleboards were produced by using $65 \%$ melamine urea formaldehyde (MUF) resin with a density value of $630 \mathrm{~kg} / \mathrm{m} 3$. Some physical (density, moisture, thickness swelling and water absorption for 2 and 24 hours) and mechanical properties of particleboards (bending strength,
\end{abstract}

Geliş: 13/06/2019, Düzeltme: 01/07/2019, Kabul: 02/07/2019 
modulus of elasticity, internal bond, surface soundness and screw holding performance) were tested according to TS EN standards. According to the test results, thickness swelling values of the test boards for 24 hour were found to be below $14 \%$. It was found that there was no statistically significant difference between all mechanical properties of the test and control boards except for screw holding performance. The values of all physical and mechanical properties of the boards indicated that they meet the minimum requirements in the P3 type (non loadbearing boards for use in humid conditions) specified in TS EN 312 (2012) standard.

Keywords: Particleboard, PMDI resin, Melamine Urea formaldehyde resin

\section{GiRIS}

$\mathrm{G}^{\mathrm{s}}$ elişen teknoloji ve değişen şartlara işletmelerin uyum sağlaması kaçınılmazdır. Günümüzde yongalevha üreticileri pazar payını arttırıcı önlemler almakta ve yenilikler yapmaktadır. Bu amaç doğrultusunda üreticiler farklı kullanım koşullarına uygun levhalar üretmek ve bu levhaları dünyada belirlenmiş uluslararası standartlara uygun hale getirmek için birtakım kimyasal maddeler kullanılmaktadırlar. Bu kimyasallardan en önemlisi PMDI tutkalıdır. Levhaların su alma, kalınlık artımı (şişme), yüzeye dik çekme direnci ve formaldehit testleri için istenilen şartlar PMDI tutkalı ile kolaylıkla sağlanmaktadır [1].

Yongalevhalar, TS EN 309 [2]'de üretim yöntemlerine ve farklı değişkenlere göre sınıflandırılmıştır. Yongalevha endüstrisinde odun, orman atıkları, yıllık bitkiler, sanayi artığı (kapak, çıtalar, testere talaşı, planya talaşı) maddeler kullanılmaktadır [3]. Ağaç malzemeler masif ve odun kompozitleri gibi farklı alanlarda kullanılmaktadır. Masif ağaç malzemenin anizotrop yapısı, geniş yüzey gerektiren kullanım yerlerinde yetersiz kalması ve ekonomik nedenlerden dolayı odun hammaddesinden teknik yollarla yongalevha, lif levha, kontrplak vb. ahşap levhalar üretilmektedir. TS EN 309 (2008)'e göre yongalevhalar; "odun parçalarından (odun yongaları, testere talaşı, rende talaşı vb.) ve/veya diğer lignoselülozik malzemelerden (keten, kenevir ipliği, kendir ipliği, suyu çıkarılmış şeker kamışı posası vb. odunlaşmış bitkilerden) elde edilen yongaların tutkallandıktan sonra, sıcak preslenmesiyle elde edilen levhalar" olarak tanımlanmaktadır [4].

Üretim proseslerinde hammadde olarak lifsel kaynaklı materyallerin kullanıldığ1 yongalevha, odun yongalarının termoset bir yapıştırıcı ile yüksek sıcaklık ve basınç altında üretilen, hem mobilya üretiminde hem de binaların farklı alanlarında kullanılan kompozit bir malzemedir. Yongalevhanın son kullanım alanları yapı işleri (duvarlar, sabit dolaplar, döşemeler, özellikle konser salonlarındaki duvar levhaları), raf ve mobilya (raflar, iç mekan mobilyaları, ofis mobilyaları, mutfak dolapları), kapı imalatı ve kapı göbeklerinde, radyo-tv-müzik seti imalatında, prefabrik evler, emprenye edilmiş olarak çiftlik evleri ve kırsal konut dış yüzeylerini kapsamaktadır [5]. FAOSTAT [6] verilerine göre; 2017 yılında Türkiye'de levha üretim miktarı $4.286 .000 \mathrm{~m}^{3}$, ithalat miktarı $78.000 \mathrm{~m}^{3}$, ihracat miktarı ise $737.000 \mathrm{~m}^{3}$ 'tür. Orman ürünleri endüstrisinde kullanılan odun hammaddesinin hemen hemen yarıs1, hammadde arzının yeterli olmaması nedeniyle tomruk ve/veya yonga olarak diğer ülkelerden ithalat yoluyla karşılanmaktadır.

İzosiyanat tutkalları II. Dünya Savaşı sırasında geliştirilmiş olup, 1970'li yılların başında, ilk olarak Almanya yongalevha pazarına girmiş olup günümüzde kompozit panellerdeki MDI bağlayıcılarının kullanımı büyük ölçüde artmıştır. Son zamanlarda MDI yapıştırıcıları tüm dünyada fazlaca büyüme 
gösteren OSB üretiminin \%20'sinden fazlasında, Avrupa ve Kuzey Amerika'da MDF fabrikalarındaki üretimlerde kullanılmaktadır [7].

Ahşap yapıştırıcı olarak izosiyanat tutkalı genel olarak iki şekilde kullanılmaktadırlar. Bunlardan birincisi; günümüzde ahşap laminasyon endüstrisinde kullanılan izosiyanat-poliol reaksiyon ürünlerinden ortaya çıkan bir üretan polimerleri, ikincisi ise; yine son yıllarda yaygın olarak yongalevha endüstrisinde kullanılan izosiyanatlardır. Yongalevha endüstrisinde genellikle kullanılan diizosiyanat tipi MDI veya 4-4'-difenilmetan diizosiyanat iken ahşap lamine esaslı ürünleri yapıştırmak için ise çapraz bağlayıcı olarak izosiyanat ile su bazlı emisyon tutkallarıdır [8]. PMDI tutkalı yurt dışından sıvı olarak temin edilmekte olup, üretim sırasında çalışanların tutkal ile herhangi bir teması olmadan, kapalı ortamda üretime verilmektedir.

PMDI yapıştırıcılar, sağladıkları yüksek yapışma mukavemeti nedeniyle ahşap panellerin yapıştırılmasında yaygın olarak kullanılırlar. Genellikle, monomer difenilmetandiizosiyanat ve metilen köprülü oligo-aromatik izosiyanatların karışımı olup her molekül üzerinde birkaç NCO (izosiyanat) grubu vardır $[9,10]$. İzosiyanat tutkalları, fenol ve melamin ile karşılaştırıldığında fiyatı yüksek ancak çok yüksek yapışma direnci ile su ve dış hava koşullarına karşı yüksek dayanıma sahiptirler [9]. Bu yapıştırıcılar, Avrupa'da formaldehit içermeyen sistemler olarak pazarlanmaktadır. Bununla birlikte, PMDI yapıştırıcıları sanayide kullanıldığında özel koruma önlemlerine ihtiyaç duymakta ve yongalevhanın dış tabakalarında kullanıldığında pres saçlarına yapışma ihtimaline karşın özel dikkat gösterilmesi gerekmektedir. Bununla birlikte sertleşmiş PMDI yapıştırıcıları için bir sağlık endişesi bulunmamaktadır [11].

Yongalevha üretiminde kullanılan izosiyanat tutkalının avantajları ve dezavantajları bulunmaktadır. İzosiyanat tutkalının avantajları; yüksek yapışma ve kohezyon direncinin yüksek olması, formülasyonunun esnek olması, su bazlı olarak hazırlanmaya uygun olması, sertleşme hızının ve sıcaklığının değiştirilebilir olması, yüksek rutubet içeriklerinde kullanılmaya uygun olması, formaldehit emisyonunun olmaması ve iyi 1sıtılılabilme özelliğiyle birlikte su almanın daha az olmasıdır. İzosiyanat tutkalının dezavantajları ise; petrol ürünü olması, su ile temasta yüksek reaktivite vermesi, maliyetinin yüksek olması, yaş halindeki örneklerin kuru halindekine göre daha az mukavemeti olması, depolama ve taşımadaki zorluklardır [7, 12].

Pan et al. [13] okaliptüs odunundan üretilmiş yongalevhalarının mekanik ve fiziksel özellikleri üzerine ağaç tür, yonga boyutu, yapıştırıcı ve kabuk içeriğinin etkisini araştırmışlardır. Levha üretiminde üre formaldehit (ÜF) ve \%4'lük PMDI (polymeric methane diphenyl diisocyanate) tutkalı kullanılmıştır. ÜF tutkal oranının artıılmasına bağlı olarak levhaların mekanik özelliklerinin iyileştiği ancak kabuk içeriğine bağlı olarak ise bu özelliklerde azalmalar tespit edildiği ifade edilmiştir.

Wang et al. [14] iç mekanlarda değerlendirmek üzere PMDI ve fenol formaldehit (FF) tutkalı kullanarak düşük formaldehit emisyonuna sahip yongalevhalar üretmişlerdir. Çalışmada yonga üzerine uygulanan PMDI/FF oranının yongalevhaların mekanik özellikleri ve formaldehit emisyonu değerleri üzerine etkileri araştırılmıştır. Araştırma sonuçları, PMDI tutkalı kullanılan yonga oranının artmasına bağlı olarak emisyon değerlerinin de doğrusal olarak azaldığını, mekanik özelliklerinin ise iyileştiğini göstermiştir. Özellikle yüzeye dik çekme direnci değerlerinde önemli artışlar olduğu ifade edilmiştir.

Yapılan bir çalışmada, çeşitli miktarlarda ÜF ve PMDI tutkalı kullanılarak $0.650 \mathrm{gr} / \mathrm{cm}^{3}$ yoğunluğunda üretilmiş yongalevhaların fiziksel özellikleri ile yüzeye dik çekme direnci değerleri araştırılmıştır. Ayrıca yapıştırma etkinliği üzerine kullanılan yağ oranı, taslak rutubeti ve pres sıcaklığının da etkisi 
araştırılmıştır. Çalışma sonuçlarına göre PMDI yapıştırıcısı ile üretilen levhaların üre formaldehitle üretilenlere nazaran fiziksel özelliklerinin daha iyi olduğu, buna ilave olarak levhaların tutkallanması için gerekli olan tutkal miktarının da PMDI kullanımı ile azaldığı ifade edilmiştir. Taslak rutubeti ve pres sıcaklığı, PMDI tutkallı levhaların yapışma etkinliğini önemli ölçüde etkilememesine rağmen, ÜF tutkalı ile üretilen levhalar üzerinde ise önemli etkileri olduğu belirtilmiştir [15].

Dukarska et al. [16] PMDI ve fenol formaldehit tutkalı kullanarak kolza yongalarından binalarda kullanılacak farklı yoğunluklarda yongalevhalar üretmişlerdir. Analiz sonuçlarına göre, kolza samanının, yüksek mukavemet gereksinimlerini karşılayan yapı yongalevhalarının üretiminde kullanılabilecek değerli bir malzeme olduğu ifade edilmiştir. Bununla birlikte, bu levhaların önemli bir avantajı, standart üretim yongalevhalardan daha iyi bir 1sı yalıtımı ile karakterize olmalarıdır.

Yongalevha üretiminde birçok yapıştırıcı madde kullanılmaktadır. En yaygın olarak kullanılanlar, fenol formaldehit, üre formaldehit, melamin formaldehit, resorsin formaldehit, izosiyanat ve termoplastik tutkallarıdır. Bu çalışma kapsamında, orta tabakada kullanılan melamin üre formaldehit (MÜF) tutkalına farklı oranlarda izosiyanat tutkalı (PMDI; polymeric methane diphenyl diisocyanate) ilave edilerek yongalevhaların fiziksel ve mekanik özelliklerinin belirlenmesi amaçlanmıştır. $\mathrm{Bu}$ amaçla, fabrika ortamında altı farklı grupta yongalevha üretilerek sonuçlar değerlendirilmiştir.

\section{MaLzeme Ve Yöntem}

\section{A. MALZEME}

Çalışmada kullanılan deneme levhaları, Kastamonu Entegre Ağaç Sanayi Gebze fabrikasından, temin edilmiştir. Yongalevhaların üretiminde kullanılan odun karışımı \%15 ladin, \%50 çam, \%20 meşe, \%10 kapak tahtası, \%5 talaş olarak belirlenmiştir. Levhaların üretiminde MÜF ve PMDI tutkalı kullanılmış olup, çalışmada MÜF tutkalı (kontrol grubu) ile PMDI tutkallarının değerlendirilmesi yapılmıştır. MÜF tutkalına ait teknik özellikler Tablo 1'de görülmektedir.

Tablo 1. MÜF tutkalının teknik özellikleri.

\begin{tabular}{lc}
\hline Tutkal Özellikleri & MÜF \\
\hline Katı Madde (\%, orta/dış tabaka) & $64.25 / 52.45$ \\
Yoğunluk g/cm & 1.285 \\
Viskozite (cps) & 562 \\
pH & 8.52 \\
Jelleşme süresi (sn) & 50 \\
Su toleransı & - \\
Mol oranı & 0.95 \\
Melamin oranı (\%) & 23 \\
\hline
\end{tabular}

\section{B. YÖNTEM}

Bu çalışmada, MÜF ve PMDI tutkallı kombinasyonlar için altı farklı grupta yongalevhalar üretilmiştir. Üretilen yongalevhalarda kullanılan PMDI tutkalı, levhaların orta tabakasına, MÜF tutkalı ise hem orta hem de dış tabakalarına uygulanmıştır. Tutkal konsantrasyonları, PMDI tutkalı için \%100, MÜF 
tutkalında ise, orta tabaka için \%64.25, dış tabakada \%52.45 olarak belirlenmiştir. Kontrol levhalarının üretiminde orta tabaka için MÜF tutkalı oranı \%7.65, dış tabaka tutkal oranı ise \%12 olarak uygulanmıştır. Deneme levhalarının (A-E grubu) üretiminde ise MÜF tutkalına ilave olarak sadece orta tabaka yongalarına $\% 0.5, \% 0.75, \% 1, \% 1.5$ ve $\% 2$ oranında PMDI tutkalı püskürtülmüştür. Levha taslağının oluşturulmasında, yonga katılım oranı orta tabaka için $\% 70$, dış tabaka için ise $\% 30$, levha kalınlıkları ise $18 \mathrm{~mm}$ olarak alınmıştır. Sertleştirici oranı, tam kuru yonga miktarına oranla \%2 olarak, parafin miktarı ise tam kuru tutkal miktarına oranla $\% 0.40$ oranında kullanılmıştır. MÜF ve PMDI tutkallarından elde edilen yongalevhaların üretim parametreleri Tablo 2'de verilmiştir.

Tablo 2. MÜF ve PMDI tutkall levhaların üretim parametreleri.

\begin{tabular}{|c|c|c|c|c|c|c|c|}
\hline $\begin{array}{l}\text { Tutkal Çeşitleri / Levha } \\
\text { Grupları }\end{array}$ & & Kontrol & $\mathbf{A}$ & B & $\mathbf{C}$ & D & $\mathbf{E}$ \\
\hline PMDI Tutkalı Oranı (\%) & Orta & 0 & 0,5 & 0,75 & 1 & 1,5 & 2 \\
\hline \multirow{2}{*}{ MÜF Tutkalı Oranı (\%) } & Orta & 7.65 & 7.65 & 7.65 & 7.65 & 7.65 & 7.65 \\
\hline & Dış & 12 & 12 & 12 & 12 & 12 & 12 \\
\hline \multirow{2}{*}{ Yonga Kat1lım Oranı (\%) } & Orta & 70 & 70 & 70 & 70 & 70 & 70 \\
\hline & D1ş & 30 & 30 & 30 & 30 & 30 & 30 \\
\hline Melamin Oran $1(\%)^{*}$ & & 21.5 & 21.5 & 21.5 & 21.5 & 21.5 & 21.5 \\
\hline Parafin Oranı (\%) & & 0.4 & 0.4 & 0.4 & 0.4 & 0.4 & 0.4 \\
\hline Sertleştirici Oranı (\%) & & 2 & 2 & 2 & 2 & 2 & 2 \\
\hline Üretim Hızı (mm/dk) & & 550 & 550 & 550 & 550 & 550 & 550 \\
\hline Kalınlık & & 18 & 18 & 18 & 18 & 18 & 18 \\
\hline
\end{tabular}

Fiziksel ve mekanik özelliklere ait test analizleri öncesi deney örnekleri $\% 65$ bağıl nem ve $20{ }^{0} \mathrm{C}$ sıcaklıkta iklimlendirme odasında şartlandırılmıştır. Çalışma kapsamına; MÜF ve PMDI tutkalları ile üretilen levhaların fiziksel özelliklerine ait; yoğunluk değeri TS EN 323 [17], rutubet miktarı TS EN 322 [18], kalınlık artımı ve su alma oranları TS EN 317 [19] standardına göre belirlenmiştir. Mekanik özelliklerinden ise, eğilme direnci ve eğilmede elastikiyet modülünde TS EN 310 [20], yüzeye dik çekme direncinde TS EN 319 [21], yüzey sağlamlık değerinde TS EN 311 [22] ve vida tutma direncinde TS EN 320 [23] standartlarına ait testler uygulanmıştır. Elde edilen sonuçların karşılaştırılmasında SPSS 16 istatistik uygulaması kullanılmıştır. Çalışmanın planlanmasında tek faktör (PMDI tutkal oranı) ve ikiden çok levha grubu olduğu için bütün testlerde basit varyans analizi kullanılmış olup değişkenlerin etkisi ortaya konulmaya çalışılmıştır. Analizler sonucunda gruplar arasında farklılıklar var ise Duncan testi yapılmıştır.

\section{Bulgular Ve TARTiȘMA}

\section{A. FIZIKKSEL ÖZELLIKLLRE AIT BULGULAR}

Deneme levhaları üzerinde yapılan yoğunluk ve rutubet değeri, 2 saat ve 24 saatlik su alma oranı ile 2 saat ve 24 saatlik kalınlık artışı değerleri incelenmiştir. Tablo 3'te farklı oranlarda PMDI tutkalı ilavesi ile üretilmiş yongalevhaların bazı fiziksel özelliklerine ait ortalama, standart sapma, homojenlik grupları verilmiştir. Yapılan basit varyans analizi değerlendirmelerine göre her bir levha türüne ait 
ortalama yoğunluk değeri, rutubet miktarı, 2-24 saatlik su alma oranı ve kalınlık artım değerleri arasındaki farklılık istatistiksel olarak \%95 güven düzeyinde önemli bulunmuştur ( $<<0.05$, Tablo 5).

Tablo 3. PMDI ilaveli MÜF tutkalından üretilmiş yongalevhaların bazı fiziksel özellikleri.

\begin{tabular}{ccccccc}
\hline $\begin{array}{c}\text { Levha } \\
\text { Grupları }\end{array}$ & $\begin{array}{c}\text { YD } \\
\left(\mathrm{kg} / \mathrm{m}^{3}\right)\end{array}$ & $\begin{array}{c}\text { RM } \\
(\%)\end{array}$ & $\begin{array}{c}\mathbf{S A O}_{\text {2saat }} \\
(\%)\end{array}$ & $\begin{array}{c}\mathbf{S A O}_{\text {24saat }} \\
(\%)\end{array}$ & $\begin{array}{c}\mathbf{K A}_{\text {2saat }} \\
(\%)\end{array}$ & $\begin{array}{c}\text { KA 24saat } \\
(\%)\end{array}$ \\
\hline KONTROL & $634 \mathrm{a}^{* *}$ & $6.93 \mathrm{bc}$ & $24.5 \mathrm{a}$ & $41.7 \mathrm{a}$ & $3.2 \mathrm{~b}$ & $7.9 \mathrm{a}$ \\
& $(10.9)^{*}$ & $(0.18)$ & $(2.3)$ & $(3.77)$ & $(0.92)$ & $(1.0)$ \\
$\mathrm{A}$ & $637 \mathrm{a}$ & $7.1 \mathrm{c}$ & $24.1 \mathrm{a}$ & $48.5 \mathrm{a}$ & $2.3 \mathrm{a}$ & $9.7 \mathrm{~b}$ \\
& $(10.8)$ & $(0.1)$ & $(3.6)$ & $(2.72)$ & $(0.71)$ & $(0.53)$ \\
$\mathrm{B}$ & $634 \mathrm{a}$ & $6.76 \mathrm{~b}$ & $26.3 \mathrm{a}$ & $73.2 \mathrm{~d}$ & $2.1 \mathrm{a}$ & $13.9 \mathrm{~d}$ \\
& $(12.7)$ & $(0.17)$ & $(1.3)$ & $(2.78)$ & $(0.53)$ & $(0.98)$ \\
$\mathrm{C}$ & $648 \mathrm{~b}$ & $7.51 \mathrm{~d}$ & $27 \mathrm{a}$ & $66.7 \mathrm{c}$ & $1.7 \mathrm{a}$ & $12.2 \mathrm{c}$ \\
& $(12)$ & $(0.04)$ & $(1.9)$ & $(4.05)$ & $(0.41)$ & $(0.62)$ \\
$\mathrm{D}$ & $633 \mathrm{a}$ & $6.42 \mathrm{a}$ & $23.4 \mathrm{a}$ & $60.9 \mathrm{~b}$ & $2.1 \mathrm{a}$ & $11.8 \mathrm{c}$ \\
& $(13.2)$ & $(0.2)$ & $(2.9)$ & $(5.04)$ & $(0.73)$ & $(1.2)$ \\
$\mathrm{E}$ & $635 \mathrm{a}$ & $6.21 \mathrm{a}$ & $32.9 \mathrm{~b}$ & $48.2 \mathrm{a}$ & $3.7 \mathrm{~b}$ & $8.5 \mathrm{a}$ \\
& $(12.8)$ & $(0.13)$ & $(6.2)$ & $(0.99)$ & $(0.98)$ & $(0.47)$ \\
& & $5-13$ & & & & 14
\end{tabular}

*: Standart sapma değerleri parantez içerisinde verilmiştir, **: Sütunda aynı harfler ile gösterilen ortalamalar istatistiksel olarak birbirinden farksız ( $\mathrm{p}<0.05)$, YD: Yoğunluk değeri, RM: Rutubet miktarı, SAO: Su alma oranı, KA: Kalınlık artışı.

$\mathrm{Bu}$ çalışmada kullanılacak olan yongalevhaların hedef yoğunluk değerleri $630 \mathrm{~kg} / \mathrm{m}^{3}$ olarak belirlenmiştir. MÜF ve PMDI tutkalı kullanılarak elde edilen levhaların yoğunlukları ise 633-6648 $\mathrm{kg} / \mathrm{m}^{3}$ arasında olduğu görülmüştür. Elde edilen yoğunluk değerleri TS EN 312 [24]'e göre belirtilen \%10'luk sınırlar içerisinde olduğunu göstermiştir. PMDI tutkalının artışına bağlı olarak yoğunluk değerlerinde farklılık gözlenmiştir. Yapılan istatistiksel analiz sonuçlarına göre $\mathrm{C}$ grubu levhalar diğer tüm gruplardan farklı olup, en yüksek yoğunluk değerine sahiptir. Üretilen levhaların rutubet değerleri ise \%6.21-7.51 arasında olduğu görülmüştür. İlgili standart, levhaların genel rutubet değerlerinin \%513 arasında olması gerektiğini ifade etmektedir. Bu bakımdan üretilen tüm levhaların rutubet değerleri, standartların belirttiği aralık içerisinde kalmaktadır. Daha önce yapılımış birçok çalışmada rutubet ve yoğunluk değerleri için benzer sonuçlar belirtilmiştir [25, 26].

PMDI tutkalı kullanılarak üretilen levhaların 2 saatlik su alma miktarları \%23.4-32.9 arasında olduğu görülmüştür. PMDI tutkalının artışına bağlı olarak (\%0.5-\%1.5 arasında) 2 saatlik su alma miktarlarında önemli bir artış gözlenmemiştir. Fakat tüm uygulamalar içerisinde \%2 PMDI tutkalı kullanılan levhaların kontrol grubu levhalara kıyasla \%34.24 oranında önemli bir artış tespit edilmiştir. Kısa süreli suda bekleme süresine (2 saat) bağlı olarak su alma oranları arasında önemli farklılıklar ortaya çıkmazken, suda bekleme süresinin artışına bağlı olarak su alma oranlarında önemli artışların olduğu gözlenmiştir (Tablo 3). MÜF ve PMDI tutkalı kullanılarak elde edilen levhaların 24 saatlik su alma miktarları ise \%41.7-73.2 arasında olduğu görülmüştür. Yapılan bir çalışmada yongalevhaların su alma oranı 2 saatte \%37-48, 24 saatte ise \%60-71 olduğu belirtilmiştir [27]. Ancak yongalevhalara ait su alma oranını sınırlandıran herhangi bir standart bulunmamaktadır.

Deneme levhalarına ait 2 saatlik kalınlık artımı değerleri \%1.7-3.7 arasında değiştiği görülmüştür. PMDI tutkalı kullanımının artışına bağlı olarak 2 saatlik kalınlık artımı değerlerinde azalmalar gözlenmiş, ancak \%2 PMDI tutkalı kullanılan levhaların kontrol grubu levhalara kıyasla kalınlık atım 
değerlerinin \%15.62 oranında artı̧̧ gösterdiği tespit edilmiştir. Genel olarak levha gruplarına ait 2 saatlik kalınlık artım değerleri arasında önemli farklılıklar gözlenmemiştir. Ancak suda bekleme süresinin 2 saatten 24 saate çıkmasına bağlı olarak kalınlık artım değerlerinde de artışlar gözlenmiştir. Farklı oranlarda PMDI tutkalı kullanılarak üretilen levhaların 24 saatlik kalınlık artımı değerleri \%7.913.9 arasında değiştiği görülmüştür. Tüm PMDI uygulamalarında elde edilen sonuçlar TS EN 312 (2012) standardında belirlenen üst limitin (\%14) altında olduğu görülmüştür. Literatürde PMDI tutkalı kullanarak yongalevha üretilen birçok çalışmada yakın sonuçlar ortaya çıkmıştır $[7,15,28,29]$.

\section{B. MEKANIKK ÖZELLIKLERE AIT BULGULAR}

PMDI tutkalı ile üretilen yongalevhaların; eğilme direnci, eğilmede elastikiyet modülü, levha yüzeyine dik çekme direnci (YDÇD), vida tutma gücü ve yüzey sağlamlığına ait ortama değerler incelenmiştir. Tablo 4'te PMDI tutkalı ile üretilmiş yongalevhaların mekanik özelliklerine ait ortalama, standart sapma, homojenlik grupları verilmiştir. Yapılan basit varyans analizi değerlendirmelerine göre her bir levha türüne ait ortalama eğilme direnci, elastikiyet modülü, YDÇD ve yüzey sağlamlığı değerleri arasındaki farklılık \%95 güven düzeyinde anlamlı olmadığ 1 anlaşılmıştır ( $\mathrm{p}>0.05$, Tablo 5). Ancak levha gruplarına ait vida tutma direnci değerleri arasında ise istatistiksel olarak farklılığın anlamlı olduğu görülmüştür $(\mathrm{p}<0.05)$. Bu nedenle yapılan Duncan testi sonuçlarına göre Kontrol, A, B ve D grubu levhaların vida tutma dirençleri arasında istatistiksel olarak fark bulunmamıştır (Tablo 4). C grubu levhalara ait vida tutma direnci değerleri $(690 \mathrm{~N})$ ise diğer tüm gruplardan düşük olup, aralarında istatistiksel olarak fark vardır $(\mathrm{p}<0.05)$.

Tablo 4. PMDI ilaveli MÜF tutkalından üretilmiş yongalevhaların mekanik özellikleri.

\begin{tabular}{cccccc}
\hline Levha Grupları & $\begin{array}{c}\text { ED } \\
\left(\mathrm{N} / \mathrm{mm}^{2}\right)\end{array}$ & $\begin{array}{c}\text { EM } \\
\left(\mathrm{N} / \mathrm{mm}^{2}\right)\end{array}$ & $\begin{array}{c}\text { YDÇD } \\
\left(\mathrm{N} / \mathrm{mm}^{2}\right)\end{array}$ & $\begin{array}{c}\text { YS } \\
\left(\mathrm{N} / \mathrm{mm}^{2}\right)\end{array}$ & $\begin{array}{c}\text { VTD } \\
(N)\end{array}$ \\
\hline KONTROL & 14.53 & 2633 & 0.55 & 1.58 & $995 \mathrm{~b}^{* *}$ \\
& $(1.86)^{*}$ & $(348)$ & $(0.1)$ & $(0.12)$ & $(43)$ \\
$\mathrm{A}$ & 14.59 & 2705 & 0.56 & 1.36 & $896 \mathrm{~b}$ \\
& $(0.93)$ & $(284)$ & $(0.08)$ & $(0.2)$ & $(95)$ \\
$\mathrm{B}$ & 15.55 & 2717 & 0.57 & 1.47 & $914 \mathrm{~b}$ \\
& $(1.92)$ & $(350)$ & $(0.02)$ & $(0.08)$ & $(85)$ \\
$\mathrm{C}$ & 14.94 & 2626 & 0.57 & 1.44 & $690 \mathrm{a}$ \\
& $(2.07)$ & $(410)$ & $(0.03)$ & $(0.13)$ & $(106)$ \\
$\mathrm{D}$ & 15.58 & 2638 & 0.58 & 1.48 & $937 \mathrm{~b}$ \\
& $(2.15)$ & $(386)$ & $(0.04)$ & $(0.07)$ & $(92)$ \\
E & 16.77 & 2665 & 0.57 & 1.61 & $898 \mathrm{~b}$ \\
& $(2.12)$ & $(374)$ & $(0.07)$ & $(0.14)$ & $(135)$ \\
TS EN 312-P3 & 14 & 1950 & 0.45 & - & 650 \\
\hline
\end{tabular}

*: Standart sapma değerleri parantez içerisinde verilmiştir, **: Sütunda aynı harfler ile gösterilen ortalamalar istatistiksel olarak birbirinden farksız ( $p<0.05)$, ED: Eğilme direnci, EM: Elastikiyet modülü, YDÇD: Yüzeye dik çekme direnci, YS: Yüzey sağlamlı̆̆, VTD: Vida tutma direnci.

MÜF ve PMDI yapıştırıcısı kullanılarak elde edilen yongalevhaların eğilme direnci değerleri 14.53$16.77 \mathrm{~N} / \mathrm{mm}^{2}$ arasında olduğu görülmüştür. PMDI tutkalının artışına bağlı olarak eğilme direnci değerlerinde genel anlamda bir artışın olduğu gözlenmiştir. Özellikle \%2 oranında PMDI tutkalı kullanılan levhaların eğilme direnci değerleri, kontrol grubu levhalarından \%15.41 oranında yüksek olduğu tespit edilmiştir. Benzer sonuçlar, PMDI tutkalı kullanılarak şeker kamışı sapından üretilmiş 
yongalevhalarda da tespit edilmiştir [9]. Ayrıca literatürde yapılan bazı çalışmalarda, levha üretimi sırasında kullanılan PMDI tutkalı katılım oranının artışına bağlı olarak levhaların mekanik özelliklerinin önemli ölçüde arttı̆̆ ifade edilmiştir [7, 14, 30].

Farklı oranlarda PMDI tutkalı ilave edilerek üretilen levhaların eğilmede elastikiyet modülü değerleri 2626-2717 N/mm² arasında olduğu tespit edilmiştir. PMDI tutkalı kullanımının artışına bağlı olarak eğilmede elastikiyet modülü değerlerinde önemli değişimler gözlemlenmemiştir. Özellikle \%0.75 oranında PMDI tutkalı kullanılan levhaların eğilmede elastikiyet modülü değerleri, kontrol grubu levhalara kıyasla \%3.19 oranında artış gösterdiği tespit edilmiştir. \%2, 4 ve 6 oranında PMDI ve EMDI tutkalları kullanılarak üretilmiş yongalevhaların eğilmede elastikiyet modülü değerleri bu çalışma sonuçları ile uyumlu bulunmuştur [7].

PMDI tutkalı ile üretilen levhaların YDÇD değerleri 0.55-0.58 N/mm² arasında olduğu görülmüştür. PMDI tutkalının artışına bağlı olarak YDÇD değerlerinde bir miktar artış gözlense de istatistiksel olarak önemli bulunmamıştır. Analiz sonuçları \%1.5 PMDI tutkalı kullanılan levhaların kontrol grubu levhalara kıyasla \%5.45 oranında artış gösterdiği tespit edilmiştir. Tüm deneme levhalarına ait YDÇD değerleri ilgili standardın belirttiği en düşük değerleri karşılamaktadır. PMDI tutkalının, düşük oranlarda bu kadar yüksek yapışma direnci vermesi birkaç gerekçe ile açıklanmaktadır. Özellikle levha üretimi sırasında oluşan, hidrojen ve poliüretan bağları yolu ile kimyasal bağlanmanın artması ayrıca PMDI tutkalının izosiyanat grupları ile odun yongasındaki rutubetin reaksiyona girerek daha yüksek mekanik bağlanma için çapraz bağlı poliüreleri oluştururlar [31]. Hafidz et al. [32] kauçuk odunu ve EMDI tutkalı kullanarak farklı üretim hızlarında elde ettikleri yongalevhaların, üretim hızının yükselmesine bağlı olarak çekme direnci gibi bazı mekanik özelliklerinde azalmalar meydana geldiğini bildirmişlerdir.

MÜF ve PMDI tutkalı kullanılarak elde edilen levhaların yüzey sağlamlığı değerleri 1.36-2.61 N/mm² arasında olduğu görülmüştür. En yüksek yüzey sağlamlık değeri \%2'lik PMDI tutkalı kullanılan varyasyonda görülmüş olup bu değer kontrol grubuna çok yakın çıkmıştır. PMDI tutkalının artışına bağlı olarak yüzey sağlamlığı değerlerinde bir miktar azalma gözlenmiş olup, levha grupları arasında anlamlı bir fark bulunmamıştır ( $>0.05$, Tablo 5). Ancak, \%2 PMDI tutkalı kullanılan levhaların kontrol grubu levhalara kıyasla \%1.90 oranında artış gösterdiği tespit edilmiştir. MÜF ve PMDI tutkalı kullanılarak elde edilen levhaların vida tutma değerleri 690-995 N arasında olduğu görülmüştür. PMDI tutkalının artışına bağlı olarak ortalama vida tutma miktarlarında azalma gözlenmiştir. Özellikle \%1.0 PMDI tutkalı kullanılan levhaların kontrol grubu levhalara kıyasla \%30.65 oranında azalma tespit edilmiştir. Dönüştürülmüş odun atıklarından PMDI ve fenol formaldehit tutkalları kullanılarak üretilmiş düşük formaldehit emisyonlu yongalevhaların vida tutma değerleri 403-746 N arasında değiştiği ifade edilmiştir [28] PMDI ilaveli MÜF tutkalından üretilen yongalevhaların bazı fiziksel ve mekanik özelliklerine ait basit varyans analiz değerleri Tablo 5 'te gösterilmiştir. 
Tablo 5. PMDI ilaveli MÜF tutkalından üretilen yongalevhaların bazı fiziksel ve mekanik özelliklerine ait basit varyans analiz sonuçlart.

\begin{tabular}{lccccc}
\hline Test Türü & $\begin{array}{c}\text { Kareler } \\
\text { Toplamı }\end{array}$ & $\begin{array}{c}\text { Serbestlik } \\
\text { Derecesi }\end{array}$ & $\begin{array}{c}\text { Kareler } \\
\text { Ortalaması }\end{array}$ & $\begin{array}{c}\text { F- } \\
\text { Hesap }\end{array}$ & $\begin{array}{c}\text { P- } \\
\text { Değeri }\end{array}$ \\
\hline Yoğunluk değeri & 3304 & 5 & 606 & 4.486 & 0.001 \\
Rutubet miktarı & 3.35 & 5 & 0.67 & 30.54 & 0.000 \\
Su alma oranı 2 saat & 279 & 4 & 69 & 5.275 & 0.005 \\
Su alma oranı 24 saat & 2458 & 4 & 614 & 53.01 & 0.000 \\
Kalınlık artımı miktarı 2 saat & 12 & 4 & 3 & 6.109 & 0.002 \\
Kalınlık artımı miktarı 24 saat & 89 & 4 & 22 & 33.81 & 0.000 \\
Eğilme direnci & 38 & 5 & 7 & 2.165 & 0.085 \\
Eğilmede elastikiyet modülü & 45639 & 5 & 9128 & 0.07 & 0.996 \\
Yüzeye dik çekme direnci & 0.003 & 5 & 0.001 & 0.139 & 0.982 \\
Yüzey sağlamlığ1 & 0.24 & 5 & 0.05 & 2.454 & 0.056 \\
Vida tutma direnci & 161650 & 5 & 32330 & 3.457 & 0.036 \\
\hline
\end{tabular}

\section{SonUC}

$\mathrm{Bu}$ çalışmada PMDI ilaveli MÜF tutkalı ile üretilmiş yongalevhaların bazı fiziksel ve mekanik özellikleri belirlenmeye çalışılmış, üretilen levhaların yoğunluk değeri, rutubet miktarı, 2-24 saatlik su alma oranları ve kalınlık artımı miktarları ile eğilme direnci, eğilmede elastikiyet modülü, yüzeye dik çekme direnci, yüzey sağlamlığı ve vida tutma gücü değerleri tespit edilmiştir. Yapılan istatistiksel analiz sonuçlarına göre, tüm fiziksel özellikler ile vida tutma direnci değerleri bakımından kontrol ve test levhaları arasında istatistiksel olarak anlamlı farklılıkların olduğu anlaşılmıştır. Ancak bu levhalar arasında eğilme direnci, eğilmede elastikiyet modülü, yüzeye dik çekme direnci ve yüzey sağlamlığı değerleri bakımından anlamlı farklılıkların olmadığı belirlenmiştir (Tablo 5, p>0.05).

Üretimi gerçekleştirilmiş olan kontrol ve test levhalarından elde edilmiş tüm fiziksel ve mekanik özelliklere ait değerler, TS EN 312 (2012) standardında belirtilen P3 tipi (nemli şartlarda kullanılan yük taşıyıcı olmayan levhalar) uygulama alanlarında aranan alt sınır veya üst sınır değerlerini karşıladığı tespit edilmiştir. Buradan da anlaşılacağı üzere, yüksek tutkal maliyetlerini de dikkate alarak yongalevha üretimi sırasında MÜF tutkalına ilave edilecek PMDI tutkalının minimum seviyede (\%0.5) kullanılmasının yeterli olacağı görülmüştür. Ayrıca PMDI ilaveli yongalevhaların banyo, tuvalet, sauna vb. gibi rutubet oranının yüksek olduğu ancak yüksek direnç özellikleri istenmeyen alanlarda da kullanılabilec eği anlaşılmıştır.

PMDI tutkalı \%100 oranında sıvıdır. Bu tutkal bünyesinde herhangi bir organik çözücü veya su bulundurmamaktadır. Odun yongalarının tutkallanması sırasında yonga rutubeti artmamakta ve presleme süresi kısalmaktadır. Bu nedenlerden dolayı PMDI tutkalı ile yapılan yongalevha üretim hızını artırmak mümkün olacaktır. Ayrıca, üretim hızının artırılması durumda işletmenin maliyet bakımından elde ettiği avantaj, tutkal maliyetinin üzerinde ise daha yüksek oranlarda PMDI tutkalı 
kullanımının değerlendirilebileceği ve bu konuda yeni Ar-Ge çalışmaları yapılmasının faydalı olacağı düşünülmektedir.

\section{KAYNAKLAR}

[1] A. Nuryawan and E. M. Alamsyah, "A review of isocyanate wood adhesive: a case study in Indonesia," In Applied Adhesive Bonding in Science and Technology, London, England, IntechOpen, 2017, Chapter 5, pp. 73-90.

[2] Yonga levhalar - Tarif ve Sinıflandırma, Türk Standartları Enstitüsü TS EN 309, 2008.

[3] Y. Göker, "Değişik Yöntemlerle Üretilmiş Yonga Levhaların Kullanım Yerleri," Laminart Mobilya ve Dekorasyon ve Sanat ve Tasartm Dergisi, c. 7, ss. 128-133, 2000.

[4] H. Kalaycığlu ve R. Özen, Yongalevha endüstrisi, Ders notları, Trabzon, 2012.

[5] H. Juslin and L. Lintu, "Responcesto changes in demand, supply of forest products through improved marketing,” XI. World Forestry Congress, Antalya, Türkiye, 1997, ss.121-135.

[6] Food and Agriculture Organization of the United Nations. (2019, 21 Mart). [Online]. Erişim: http://www.fao.org/faostat/en/\#data/FO

[7] A. N. Papadopoulos, C. A. S. Hill, E. Traboulay and J. R. B. Hague, "Isocyanate Resins for Particleboard: PMDI and EMDI," European Journal of Wood and Wood Products, vol. 60, no. 2, pp. 81-83, 2002.

[8] W. E. Johns, "Isocyanates as Wood Binders-A Review," The Journal of Adhesion, vol. 15, no. 1, pp. 59-67, 1982.

[9] M. Dunky, Adhesives in the wood industry, Handbook of Adhesive Technology, In A. Pizzi, K. L. Mittal (eds.), New York, ABD, Chapter 47, pp. 872-941,2003.

[10] D. Sandberg, "Additives in wood products - today and future developments," Environmental Impacts of Traditional and Innovative Forest-based Bioproducts, Switzerland, Springer Singapore, 2016, pp. 105-172.

[11] D. Grunwald, "Adhesives for wood-based boards," Presented in 1st Euro-Asian International Short-Course on Wood-based Composites, Trabzon, 2014.

[12] Z. Pan, A. Cathcart and D. Wang, "Properties of Particleboard Bond with Rice Bran and Polymeric Methylene Diphenyl Diisocyanate Adhesives," Industrial Crops and Products, vol. 23, no. 1, pp. 40-45, 2006.

[13] Z. Pan, Y. Zheng, R. Zhang and B. M. Jenkins, "Physical Properties of Thin Particleboard Made from Saline Eucalyptus," Industrial Crops And Products, vol. 26, no. 2, pp. 185-194, 2007. 
[14] S. Y. Wang, T. H. Yang, L. T. Lin, C. J. Lin and M. J. Tsai, "Properties of LowFormaldehyde-emission Particleboard Made from Recycled Wood-Waste Chips Sprayed with PMDI/PF Resin,” Building and Environment, vol. 42, no. 7, pp. 2472-2479, 2007.

[15] A. Papadopoulos, "Property Comparisons and Bonding Efficiency of UF and PMDI Bonded Particleboards as Affected by Key Process Variables,” BioResources, vol. 1, no. 2, pp. 201-208, 2006.

[16] D. Dukarska, R. Czarnecki, D. Dziurka and R. Mirski, "Construction Particleboards Made from Rapeseed Straw Glued with Hybrid pMDI/PF Resin," European Journal of Wood and Wood Products, vol. 75, no. 2, pp.175-184, 2017.

[17] Ahşap esaslı levhalar-birim hacim ağırlı̆ıııı tayini, Türk Standartları Enstitüsü TS EN 323, 1999.

[18] Ahşap esasl levhalar-rutubet miktarının tayini, Türk Standartları Enstitüsü TS EN 322, 1999.

[19] Yonga levhalar ve lif levhalar-su içerisine daldırma işleminden sonra kalınlı̆̆ına şişme tayini, Türk Standartları Enstitüsü TS EN 317, 1999.

[20] Ahşap esaslı levhalar-eğilme dayanımı ve eğilme elastikiyet modülünün tayini, Türk Standartlar1 Enstitüsü TS EN 310, 1999.

[21] Yonga levhalar ve lif levhalar-levha yüzeyine dik çekme dayanımının tayini, Türk Standartları Enstitüsü TS EN 319, 1999.

[22] Ahşap esaslı levhalar-yüzey sağlamlığı-deney metodu, Türk Standartları Enstitüsü TS EN 311, 2005.

[23] Yonga levhalar ve lif levhalar, vida tutma mukavemetinin tayini, Türk Standartları Enstitüsü TS EN 320, 2011.

[24] Yonga levhalar-özellikler, Türk Standartları Enstitüsü TS EN 312, 2012.

[25] C. Guler, H. I. Sahin and S. Yeniay, "The Potential for Using Corn Stalks as a Raw Material for Production Particleboard with Industrial Wood Chips," Wood Research, vol. 61, no.2, pp. 299-306, 2016.

[26] H. İ. Şahin, M. Yalçın ve N. Yaglıca, "Orta Tabakası Kompost Atığı İlaveli Yongalevhaların Vida Tutma Gücü ve Isı İletkenlik Değerlerinin Belirlenmesi," Artvin Çoruh Üniversitesi Orman Fakültesi Dergisi, c.18, s.2, ss. 121-129, 2017.

[27] H. Kalaycığlu, "Bitkisel atıkların yongalevha endüstrisinde değerlendirilmesi," ORENKO 92 1. Ulusal Orman Ürünleri Endüstri Kongresi, Trabzon, Türkiye, 1992, ss. 288-292.

[28] S. Y. Wang, T. H. Yang, L. T. Lin, C. J. Lin and M. J. Tsai, "Fire-Retardant-Treated Lowformaldehyde-Emission Particleboard Made from Recycled Wood-Waste," Bioresource Technology, vol. 99, no. 6, pp. 2072-2077, 2008. 
[29] M. J. Saad and I. Kamal, "Mechanical and Physical Properties of Low Density Kenaf Core Particleboards Bonded with Different Resins," Journal of Science and Technology, vol. 4, no. 1, pp. 17-32, 2012.

[30] A. H. Grigoriou, "Straw-Wood Composites Bonded with Various Adhesive Systems," Wood Science and Technology, vol. 34, no. 4, pp. 355-365, 2000.

[31] W. Chelak and W.H. Newman, "MDI high moisture content bonding mechanism, parameters and benefits using MDI in composite wood products," Proceedings of the 25th International Symposium of Washington State University on Particleboard/Composite Material Symposium, Washington, ABD, 1991, pp. 205-229.

[32] M. Y. Ab Hafidz, A. F. Mohd and M. Zulkifli, "Mechanical Properties and Formaldehyde Emission of Rubberwood Particleboard Using Emulsified Methylene Diphenyl Diisocyanate (EMDI) Binder at Different Press Factor Continuous Press," International Journal of Engineering and Technology, vol. 7, no. 4, pp. 335-338, 2018. 